\title{
Workplaces as Learning Spaces: Increasing Productivity in Workplaces in Thailand
}

\section{Areeya Rojvithee}

This article ${ }^{9}$ reports on a strategy for increasing productivity of labour in the workplaces through an evaluation of learning and training methodology applied at selected workplaces in Thailand. A public-private partnership project initiated by the government allocated seed money to run the pilot project in various establishments including SMEs. With the cooperation of the private sector, a consultant team was allowed to access the company, analysing the process of work to find the weak points to improve, then organising suitable training courses for target employees in the workplaces. After the training the employees were expected to apply the new knowledge, skills and competencies to their work. The consultants' assessment of their work indicated that productivity was increasing. Furthermore it was seen as a good strategy to demonstrate the importance of workplace-based training for improving labour productivity and to encourage SMEs to continue to conduct the learning and training to increase productivity in their workplaces. The final results were seen as promising not only in reducing operational cost of establishments but also in potentially enhancing competitiveness of Thai industries as a whole in the world market. The strategy is discussed as an example of how national initiatives can aim to change the 'organizational space' that creates an organisation's capacity to use and produce skills, organise and reward work, in pursuit of productivity gains.

Key words: productivity of labour, work-based training, SME, policy implementation

\footnotetext{
${ }^{9}$ The author is grateful to Prof Dr. Karen Evans for her guidance, advice and editing of this article.
} 


\section{Background}

The success of each organisation depends on the quality of human resources working in that workplace. So, people are the core assets of the organisations whether they are big or small. According to this perspective, the ability, knowledge, competency and skills of human resource must be continuously sharpened or upgraded to keep up with new development of technologies, processes or systems of working and new strategies are sought to improve the productivity of workforces.

Nowadays, the issue of using the workplace as a learning centre has become increasingly important. Workplaces connected to the globalised economy have been transformed as new technologies, changing patterns of work, growth of the knowledge economy and the growing use of high performance work practices are transforming the ways in which work is organized (Ashton and Sung 2002). One of the major challenges for any country is to improve their productivity and competitiveness. A key strategy for achieving that goal is the promotion of workplace learning, in the context of lifelong learning, to ensure that workers' skills are constantly renewed and adapted, and to prepare them for a wide variety of potential jobs. Also the new ILO Human Resources Development Recommendation (2004) stresses the importance of Member States' promotion of the expansion of workplace learning and training. (ILO, 2004, P.4 ) Policy of the Thai Government

The Thai government has placed particular importance on the quality of human resources which can be spotted in various articles in the current 11th National Social and Economic Development Plan (2012-2016) as follows:

- Promoting Lifelong learning that involves a process of continuous study, skill development to enhance resilience in life and adaptation to global changes in the 21 st century.

- Improve skills and capacity of the workforce to align with the production of goods and services to build a better economy. Creating Networks to produce and develop the labor force partners in parallel with international learning networks.

- Restructure the production system to a focus on knowledge, science and technology with high productivity by setting up the target to increase the Labour Productivity by at least 3 per cent per annum .

- Promoting SMEs by providing support on human resource skills that are relevant to business requirements. Improve the knowledge and skills of firms in production, marketing and IT, and promote the application of science and technology, local insight, innovation and good governance. 
Further, measures should be established to assist SMEs in gaining access to sources of finance.

The research by the World Bank showed that Thailand's competitiveness, as ranked by IMD and WEF in 2010, was 26th and 38th respectively, with little improvement during the course of the Tenth Plan. Low productivity has become a constraint on Thailand's competitiveness and its sustainable development. Also the study of the Thailand Productivity Institute in 2015 showed that the major obstacle for the foreign investment in Thailand was the skilled labour shortage and low labour productivity. Thailand Development Research Institution (TDRI) suggests that low productivity in many Thai workplaces is a threat to the international competitiveness of Thai industries which in turn will affect the Thai economy as a whole.

To solve this problem, the Thai government has issued a policy to increase the productivity of Thai employees in target industries. The government has assigned the Department of Skill Development, Ministry of Labour to be the core organisation to manage this project for 4 fiscal years (2013-2016). First the government allocated a budget to run the pilot project in a sector of the target industries for a period of 6 months in the year 2013 to assess the feasibility of the project. On the basis of satisfactory results, additional budgets were allocated in the next fiscal years with slight differences introduced into the Model of learning and training which will be explained.

This initiative is connected to a parallel decision of the Thai government, which issued a Cabinet Resolution on November 20, 2012 agreeing with the proposal of the National Wage Committee of Thailand to increase the National Minimum Wage to 300 Baht (7.5 Euro) per day per person for all employees in the country. The Cabinet Resolution came into effect on the 1st of January, 2013. This means that all employers including Small and Medium Enterprises (SMEs) have to bear the increase in their expenditure or operational cost to pay salary or remuneration to their employees. In order to be fair to the employers and to reduce their burden, the government has applied the concept of increasing productivity in the workplaces, with the aim that if productivity increases, the employers can reduce their operation costs in all aspects. They will eventually gain, not lose. So, the government's allocation of resources to start up the project "Increasing Productivity in the Workplaces" has charged the Department of Skill Development with working closely with the establishments, analysing their losses, their weak points and solving problems for the final end which is increasing productivity, becoming more profitable and willing to pay more salary to their employees. This is described as a 'win-win' situation.

This article focuses on the content of the project for the fiscal year of 20132015. As the Thai fiscal year started on the 1st of October to 30th of September of 
each year, the current project of year 2016 is being implemented and the project does not yet have results for that period. The data and information in this article is based on the information provided by the DSD in the form of the project proposal, guide book for implementation and the report of project implementation.

\section{Concept of Increasing Productivity}

To increase productivity in the workplaces there are many strategies that have been identified.

In order to apply the right strategy the understanding of the concept of "productivity" is necessary. It is usually defined as the relation between the output (produced goods) and the input (consumed resources) in the manufacturing transformation process. Productivity is connected to the use and the availability of resources. Productivity is reduced if a company's resources are not properly used or lacking. Productivity is strongly linked to the creation of value. Thus high productivity is achieved when activities and resources in the manufacturing transformation process add value to the produced products. Furthermore, the opposite of productivity is represented by waste which must be eliminated in order to improve productivity (Tangen, 2002).

The definition of "productivity" in this article as used in the Handbook of the project means the ratio of the quantity of output to the quantity of the input in the production process. The inputs are labour (employees); raw materials; machine and money. Or we can say how much output we can gain from the capacity of production of 1 unit of the input. The measurement of the increasing productivity is the ratio of the outputs divided by the inputs: if the result is greater than 1 meaning that it is progressive productivity, but if the result is less than 1 , it means a regressive productivity.

If the production process consists of various factors of inputs and output, the result is called the total factor of productivity.

Labour productivity is the amount of production of 1 person or 1 working hour.

Capital productivity is the amount of production of 1 financial cost.

Total factor productivity is the increasing of output due to other factors such as technology development; improving of management and improving of the quality of human resources in the workplaces. 
There are many strategies for increasing productivity but this project is focusing on reducing loss or waste in the production process such as the remainder of the raw material and the processed material; time; electricity; money which cannot be brought back to reuse or recovered.. According to this perspective, waste in the production process means that performance that does not create value added to the products or services or give satisfaction to customers. The reduction of the cost can be achieved through various factors of production process such as labour cost or employees' wages, cost of raw material, cost of machine and tools, cost of production process and the administrative cost. Reducing cost does not mean to pay less money but it means to utilize the money as to the value of products and create satisfaction among customers.

Strategies for productivity gains have to be interpreted in context and according to the organizational space that creates or limits an organisation's capacity to use and produce skills, organise and reward work. The organisational space, according to Hefler and Markowitsch 2012, is characterised by institutionalised processses that are specific to the particular society. Since, in the organisational space, employees are rewarded for their productivity according to their adaptation to the organisation, workplace learning plays a crucial role. Where the organisation is itself confronted with the need to change its processes and practices, the organisational learning space has to be expanded by bringing in external resources to support training and development.

\section{Process of the Project's Implementation}

Department of Skill Development (DSD) has drafted the project proposal to request a budget from the Budget Bureau of the year 2013 when 12,000,000 THB (Twelve Million Thai Bath, c. 300,000 Euros) was allocated by the government to run this first pilot project.

Then DSD drafted the Term of Reference (TOR) to recruit a Consultant Companies to work for this project.

DSD's officials in charge for implementation of this project were trained to understand the objectives of the project, the meaning of productivity and how to improve, the selection of the consultant companies according to the public rules and regulations and to set up the key indicators to monitor and to evaluate the project.

DSD staffs have to work closely with the team of consultants who have to transfer knowledge and skills to the officials of DSD. The officials monitor closely the whole work process in each company with different problems and issues to solve. The final result of the project was to get the group of qualified staff of DSD 
who has been trained both in theory and practices from the consultants to work for the Department in regular work to help establishments to survive any crisis.

Then DSD announced the objectives and content of the project to the private sectors or establishments willing to join the project to increase productivity in workplaces. If the private sectors wanted to join DSD, strong commitment from the management and employees of each establishment was needed to work closely with DSD' staff and the team of consultants.

The duration for DSD to work in each establishment was 6 months. This included first visit to discuss with the authority at administrative level to get the consent and the assignment to work in any section, listening to all problems, collecting information and analysing, then proposing the plan to improve productivity by designing the training courses both in theory and practices to train employees/ employers to achieve the goal.

After all preparation works were done, the training was ready to start in the assigned section in different contents and different styles of the courses. It was 2 way communications between the trainer and the trainees, mutual consultation to improve all the process of work to increase productively, to reduce waste and to minimize the operation cost.

There was assessment and evaluation of all trained employees/ administrative staff to be sure that they could adapt themselves to the improvement of the working process and could transfer knowledge and skills to their colleagues in other sections.

After implementing the new system for some time, the measurement has been done to see the result, to assess whether the system could reduce the waste and increase the productivity as in the standard that had been set.

Expected outcomes of the project were:

The increase in knowledge and skills among employees facilitated by the work of consultant team and the utilization of knowledge learnt in the real working situation were expected to reduce waste in the working process. The consequent improvement in labor productivity in establishments was expected to include loss reduction and the increase in value added and productivity.

The application of the methodology and strategy acquired from consultant team were to be used in other sections of the establishments. The trained officials of DSD themselves were expected to use their expanding knowledge and skills for productivity to continue their work to support establishments as their regular work 


\section{Summary of the Implementation}

DSD started running the pilot project on Increasing Productivity in the Workplaces through the knowledge and skill development of employees in the year 2013 to study all the processes of work with the budget 12 million Baht. There were 18 establishments in 8 provinces in Central Region joining to work. The establishments found that they could reduce their waste; cost of energy and utility such as electric and water; operation cost by 192 Million Baht. The project has been modified and approved to continue in the next Fiscal Year.

In the year 2014, DSD received a greater budget. It included 75 million Baht (approximately 1.9.million Euros) to run the project including employing Consultant Companies to work in depth with 200 establishments in the 10 focused industries. The number of employees trained in the workplaces was 20,092 persons. The establishments could reduce all related costs and created value added by 1,682 million Baht per year. Also the 278 officials of DSD were trained to increase knowledge and skills in all processes to increase productivity in the workplaces from the Consultant Companies. These officials worked as coordinators and supervisors of the project for each area and establishment.

In the year 2015, DSD received 67,500,000 Baht from the government to implement this project by focusing on Small and Medium Enterprises (SMEs) with 50-200 employees in 19 business sectors. There were 260 establishments that joined the project. The results of the implementation were as follows:

Promoting Skill development among employees in the workplaces of the target establishments by improving the production process, reducing work duplication and loss, organizing the intensive learning and training courses for both hard and soft skills attended by at least $50 \%$ of the total amount of employees in each establishment joining this project, 16,796 employees having been trained to acquire multi- skills to work with potential to analyse and solve the problems occurring during working and cooperating with employers to improve all the process of work, creating good labour relations in the workplaces and creating the value added altogether 603 million Baht after the completion of the project.

DSD assigned officials in each Skill Development Institute and Center in each province to work closely with the team of consultants who are the knowledgeable in such field from the well- known universities in Thailand. The officials were transferring knowledge and skills both theory and practices from the consultants to achieve the objectives of the project. With this project DSD could get good Model of increasing productivity in the workplaces of Thai industries and got qualified officials to work. 
DSD has established the Consulting Centre for Productivity in each province to: (1) Give preliminary advice to establishments to improve the production process by applying the Up-Grading Training Courses that are available in DSD in various trades of training both hard and soft skills.

(2) Give technical advice to the establishments participating in this project in previous years to continue to improve productivity in other sectors within the establishments. If they require financial assistance, they can borrow money from the Skill Development Promotion Fund with 3\% interest rate per year. This fund has been managed by DSD under the Skill Development Promotion Act 2002.

(3) The current year 2016, DSD received 67.5 million Baht to run this project. 260 SMEs in 20 business sectors with employees from 50-200 and 201 up are expecting to join. The target employees to be trained are 10,000. This year the project is in progress so no result to show.

\section{The Main Contents of Training}

After analysing and identifying the causes of problems, the consultants set up plans and curriculums to train the employees. The problems of each establishment were different so the strategies to solve those problems were differed between the various consultants and establishments. The courses of training might be hard skills to operate the machine and production process; to utilize the materials. Soft skills training included team working; problem solving; innovative thinking and leadership.. After the training, the new concept of work should be applied. Details of the model implemented and records that enabled comparisons of the results had to be kept to see whether it was improved or not. These were presented to the top management to show the result and they had to sign to accept the result that benefited them.

Some tools/ techniques that are typically used to improve productivity include quality control processes including Quality Control Circles (QCC), tools for improving orderliness $(5 \mathrm{~S})$, daily steering, process improvement including work study/time study and continuous improvement and waste reduction.

The application of these tools/ techniques depends on the situations and problems that need to be solved or improved to increase productivity/ value added. These tools have their specific purposes. to improve the processes of production or processes of working. Most of the tools have been derived from the Toyota Production System (TPS), a recognized source of multi-purpose approaches for developing people in the global manufacturing environment. 
The process of implementation in the SMEs involved groups of workers in the same unit brain storming on ideas with their supervisor, identifying possible activities in order to solve problems related with Quality Control in their unit. This process used a range of diagnostic and planning and problem-solving tools, selecting those most suitable to the case to be improved. For example, 'PDCA' focuses on the work process to get the work done smoothly and efficiently. Starting with careful planning $(\mathrm{P})$ then work is continued to follow the plan or doing (D). After doing the work for some time checking $(\mathrm{C})$ the process of work regularly is needed to improve and action (A) by setting up standard of work improvement is taken. Similarly, principles of problem solving by Quality Control Circles follow defined steps in clarifying, analyzing, taking action and preventing future occurrences. Waste in the production process is an important area for diagnosis of problems and action-taking, depending on the nature of work and problems. Sources of waste through overproduction, stock control; defects; excess processing; waiting time, motion and transportation can be identified in ways that are amenable to improvements.

From the above tools that the consultant selected for improving productivity in each unit, the curriculum was designed to be relevant to the specific target group. The consultants then carried out the training, with testing of employees' understanding, before implementing the new model of work and finally evaluating the result, whether improving or not. If no improvement, the consultants had to solve the problems on the spot to be sure that they fulfilled the objective. The DSD officials were witnessing and learning from all processes from the consultants and also supervised the implementation of the project according to the Terms of Reference (TOR). In order to know the result of learning and training in the workplaces, in-depth interviews were conducted with key informants in each target workplace on how the model and methodology were implemented and how far the training and other forms of learning were contributing to increases in productivity.

\section{Discussion of results to date}

This initiative can be considered as an example of the organisational spaces of SMEs have been expanded to become particular kinds of learning spaces, by the strategic use of consultants backed by a national governmental policy. Where the results of the of the research came out positively, employees learned new hard and soft skills and effectively applied them in their daily working life. Employers were satisfied with the reduction of the operation cost. They gained new qualified employees with productivity increasing. Employers realized the benefit of training so they wanted to extend the training to other sections in their workplaces at their 
own cost. Considering roughly in financial terms the amount of government investment, the benefits can be seen as in the Table 1:

\begin{tabular}{|l|l|l|l|}
\hline Year & $\begin{array}{l}\text { Amount of } \\
\text { Budget } \\
\text { Allocated } \\
\text { (Thai Baht) }\end{array}$ & $\begin{array}{l}\text { Value Added } \\
\text { Gain per year } \\
\text { Million Thai Baht }\end{array}$ & $\begin{array}{l}\text { Number of establishments that } \\
\text { joined/ Number of trained } \\
\text { employees in this project. }\end{array}$ \\
\hline 2013 & $12,000,000$ & $192,000,000$ & $18 /$ NA. \\
2014 & $75,000,000$ & $1,682,000,000$ & $200 / 20,092$ persons \\
2015 & $67,500,000$ & $1,206,000,000$ & $260 / 16,796$ persons \\
2016 & $67,500,000$ & ----- & $260 / 10,000$ \\
\hline
\end{tabular}

Table 1: Budget Allocated, Value Added and Numbers Reached

The figures above have been calculated by the consultant team after completing the project each year and were used to justify requesting budget for the following year. The project covered only some establishments that joined the project. The total number of establishments in Thailand is 359,853 and total employees are 8,634,825 persons. (Ministry of Labour, 2016).

The qualifications and experiences of the consultant teams have been shown to be important for the success of the project. Usually the consultants had academic backgrounds and experiences that enabled them to analyse the causes of the problems and to know how to tackle and to solve them. Solving the problems needs to deal with people on the spot as they are core actors so their attitude and cooperation is necessary for success. Above all, the top management of each establishment has to take responsibility and they play a vital role to support the process. They are those who gain the benefit of the result.

It is instructive to consider these observations in the light of experiences in working with the these kinds of tools and approaches in contrasted European contexts. Parallel research undertaken in Sweden has studies two national programmes for implementating lean approaches, the first an industrial programme formed to implement approaches based on an interpretation of Toyota's way of managing its operations in 60 medium -sized manufacturing companies, the second programme focused on public authorities (Eklund et al, 2015). As in the Thai case, the findings, based on documentary analysis, interviews and questionnaies, showed considerable variation in how the methodology was interpreted and implemented. A similar range of tools to the Thai case was adopted, ranging from organizational tools (focusing on the organization of work and work-flow) to technical/economic (focusing on cost-cutting) tools. In some of the organizations, reflecting Swedish socio-technical traditions, implementation was accompanied by a drive to develop a high-participation as well as high-performance workplace, with a pronounced focus 
on improving working conditions. As in the Thai case, the active ownership of top management and politicians was important for the introrduction of the change, and also for its sustainability. An interesting observation from the Swedish cases, which has yet to be tested in the ongoing Thai programme, was that in organizations where the emphasis was on technical/economic tools rather than organizational tools, many Swedish employees considered the working environment to have deteriorated and the changes to be unsustainable. In particular, more repetitive work and less mentally stimulating tasks arising from the use of some of these tools proved counter-productive and led some companies to introduce job rotation to offset some of the negative effects on employees' capabilities. There was also reluctance of some managers to 'open up' their efforts to criticism. By contrast, the use of organisational tools, when combined with a participative approach, appeared more likely to generate sustainable change. The comparison of findings from the Thai and Swedish programme is the kind of activity that the ASEM Research Network can usefully learn from, keeping the contrasting traditions and societal contexts in view.

\section{Conclusion}

The evaluation indicates how changes to the organisational space have expanded the learning space in Thai SMEs industries, in particular directions. The Thai policy implementation reported in this article has indicated how productive gains can be achieved and identifies some of the factors that have been important in achieving those changes. In particular, the use of consultants to bring diagnostic experience and methodological expertise into the establishments as a basis for planning change and designing tailor-made workplace training linked that change. The specific organizational spaces in this example appear to have been both expanded to incorporate a wider range of learning activities, and transcended by the strategy of training a cadre of consultants who can operate in their industry sectors and have their own trajectory of development as 'industry educators'.

As the ASEM Research Network Coordinator (Evans, in this volume) has noted, the work is ongoing and unanswered questions are how sustainable this approach can be. From the learning spaces perspective, how the employees' experience these changes, beyond the promise of wage increases, is a matter requiring further research and analysis, with much scope for Asia-Europe comparisons. 


\section{References}

Ashton, D. \& Sung, J. (2002) Workplace Learning and High Performance Working, Chapter 4, Supporting Workplace Learning for High Performance Working, Geneva: International Labour Office.

Department of Skill Development (2015). Guidelines for Consultant to Implement the Project for Increasing Productivity in the Workplaces.

Department of Skill Development (2015). Guidelines for Technics and Inspection of the Project Increasing Productivity in the Workplaces.

Department of Skill Development (2015). Training Document of the Project Increasing Productivity in the Workplaces for Official of DSD.

Eklund, J., Lindkvist, A.H. and Lindskog, P. (2015). Lean implementation, work environment and sustainability. In Elg, M., Ellstrom, P-E and Tillmar, M. Sustainable Development in Organisations. London: Edward Elgar.

Hefler, G. and Markowitsch, J. (2012) Bridging institutional divides linking education, careers and work in 'organisational space' and 'skills'space' dominated emplyment systems. In Eds Brooks, R. et al., Changing Spaces of Education. Abingdon: Routledge.,

National Social and Economic Development Board (2012). The 11th National Social and Economic Development Plan.

Poapongsakorn N., Y. Chalamwong, and D. Lathapipat (2011), "The Linkage between Educational Institutionsand Labor Market: Quality of the Graduates and Lack of Qualified Labor," Thailand Development Research Institution, a paper presented at the TDRI annual symposium 2011 (in Thai).

Tangen, S. (2002). Understanding the concept of productivity. In Proceedings of the 7th Asia-Pacific Industrial Engineering and Management Systems Conference, Taipei..

Thailand Productivity Institute (2015). The Report of the survey of Productivity and Atmosphere of Investment in Thailand.

International Labour Organisation (2004). Human Resources Development Recommendation, 2004 (No. 195) Recommendation concerning Human Resources Development: Education, Training and Lifelong Learning Adoption: Geneva, 92nd ILC session (17 Jun 2004) - Stat

International Labour Organisation (2007). Regional Workshop on Improving Workplace Learning in Asia and the Pacific, Seoul, the Republic of Korea, 15-17 May 2007. (web pdf ) ILO/SKILLS-AP/KRIVET ISBN: 9789221209980; 9789221209997 
Wongboonsin, P. and Rojvithee, A. (2007). The "Competence Development as Workplace Learning in Thailand" for ASEM Research Seminar organized by Leopold-Franzens-University of Innsbruck, Institute of Educational Sciences, Austria during 25 - 27 September 2006.

\section{Websites}

www.dsd.go.th

www.mol.go.th

www.nesdb.go.th

www.ilo.org/publns

https://bobsleanlearning.wordpress.com/category/lean-basics/5-whys/

http://www.linkedin.com/in/bobhubbard

www.worldbank.org 